\title{
Universidad y Filosofía de la Praxis Artística: teatro, pensamiento teatral, Ciencias del Teatro
}

\author{
University and Philosophy of the Artistic Praxis: \\ theatre, theatrical thinking, Theatre Sciences
}

Jorge Dubatti

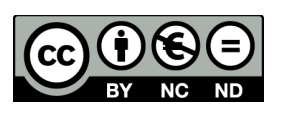

Esta obra está bajo una licencia Creative Commons Reconocimiento-No comercial-Sin Obra Derivada 


\title{
Universidad y Filosofía de la Praxis Artística: teatro, pensamiento teatral, Ciencias del Teatro \\ University and Philosophy of the Artistic Praxis: theatre, theatrical thinking, Theatre
}

\author{
Jorge Dubatti ${ }^{1}$ \\ Universidad de Buenos Aires \\ Argentina
}

Recibido: 13 de setiembre de 2019 Aprobado: 18 de noviembre de 2019

\begin{abstract}
Resumen
Asistimos a nuevos desafíos para la investigación artística fuera y dentro de la Universidad. Se ha puesto en primer plano la necesidad de practicar y pensar desde nuevas aproximaciones las relaciones entre arte y conocimiento, y especialmente los vínculos entre la praxis artística y la ciencia en el marco universitario. Este trabajo propone articular las nociones de teatro, pensamiento teatral y Ciencias del Teatro como diferentes formas de producir conocimiento desde el acontecimiento teatral, es decir, Filosofía de la Praxis Teatral. Se promueve la identificación de cuatro figuras fundamentales en la producción de conocimiento desde/para/sobre la praxis artística: el artista-investigador, el investigadorartista, el artista asociado a un investigador no-artista especializado en arte y el investigador que (sin ser artista) produce conocimiento participando en el acontecimiento artístico (ya sea por su estrecha relación y familiaridad con el campo artístico o por su trabajo en el convivio como espectador; es el investigador que ubica su laboratorio en el acontecimiento teatral, no solo en el gabinete científico), con sus respectivas combinaciones. Se propone además distinguir un pensamiento teatral sustentado o no sustentado por las prácticas artísticas. Finalmente, pensar el teatrista como intelectual específico, en paradójica complementariedad con la crisis del teatrista "ilustrado".
\end{abstract}

Palabras clave: teatro; universidad; producción de conocimiento; ciencias del arte; sujetos de la investigación artística

1 Director del Instituto de Artes del Espectáculo de la Facultad de Filosofía y Letras de la Universidad de Buenos Aires, Argentina y profesor titular a cargo de la Cátedra de Historia del Teatro Universal de la carrera de Artes, de la misma universidad. Doctor en Historia y Teoría de las Artes por la Universidad de Buenos Aires. ORCID: 0000-0002-8304-7298. Correo electrónico: jorgeadubatti@hotmail.com

ESCENA. Revista de las artes, 2020, Vol. 80, Núm. 1, pp. 8-31 ISSN 2215-4906 


\begin{abstract}
We are witnessing new challenges for artistic research in and outside the University. The need to practice and think from new approaches to the relationship between art and knowledge has been set at the forefront, especially the links between artistic practice and science in the university framework. This paper proposes to articulate the notions of theater, theatrical thinking and theater sciences as different ways of producing knowledge from theatrical discovery, that is, Philosophy of Theater Praxis. The article promotes the identification of four key figures in the production of knowledge from/ to/on artistic practice. They are the artist-researcher, the researcher-artist, the artist associated with a non-artist researcher specialized in art, and the researcher who (without being an artist) produces awareness by participating in the artistic event (due either to his closeness with the artistic field or to his work in coexistence with his role as spectator; it is the researcher who places his/her lab in the theatrical event, not just in the scientific cabinet), with their respective combinations. It also intends to distinguish a theatrical thought supported or not by artistic practices. Finally, to think of the teatrista (theater all-rounder) as a specific intellectual, paradoxically complementary to the crisis of the "enlightened" teatrista.
\end{abstract}

Keywords: theatre; university; knowledge; art; research 
Pues no cabe duda de que la mayor parte de la labor de un autor al componer su obra es labor crítica; la labor de tamizar, combinar, construir, expurgar, corregir, probar; esta faena espantosa es tanto crítica como creadora. Hasta sostengo que la crítica empleada en su propio trabajo por un escritor adiestrado y experto es la crítica más vital, la de categoría más elevada.

(Eliot, 1994. p. 33)

\section{Hacia una nueva investigación artística}

En los últimos años han surgido nuevos desafíos para la investigación artística fuera y dentro de la Universidad. Se ha puesto en primer plano, nacional e internacionalmente, la necesidad de practicar y pensar, desde nuevas aproximaciones, las relaciones entre arte y conocimiento y, especialmente, los vínculos entre la praxis artística y la ciencia en el marco universitario. De allí la necesidad-como señalamos en nuestra Filosofía del Teatro (Dubatti, 2014, párr. 11-22) - de las Ciencias del Arte en su aporte específico.

Llamamos Ciencias del Arte, y dentro de ellas, Ciencias del Teatro², al conjunto de numerosas disciplinas científicas que producen discursos sobre el arte/el teatro, muchas en relación con otros campos científicos (Ciencias Sociales, Ciencias Naturales, Ciencias de la Educación, Ciencias Exactas, entre otras), pero también muchas de ellas dotadas de un carácter singular, específico. Esas disciplinas son científicas porque, a diferencia de la doxa (saber acrítico y fácilmente refutable), producen sobre el arte/el teatro un conocimiento riguroso, sistemático, crítico, fundamentado y validado por una comunidad de expertos o especialistas.

Es un error frecuente pensar que, bajo el nombre de Ciencias del Arte, se intenta otorgar estatuto de ciencia al arte, es decir, sostener que el arte es una ciencia o que para hacer arte (pintar, bailar, cantar...) hay que ser científico. Un malentendido que no permite comprender la naturaleza y función de las Ciencias del Arte y que algunos grupos o sectores se empeñan en ratificar. Se trata, por el contrario, de afirmar que existen las Ciencias del Arte porque se puede producir discurso científico sobre el arte. Así la Teatrología o Ciencias del Teatro reúne numerosas disciplinas científicas diversas: Historia del Teatro, Semiótica del Teatro, Antropología Teatral, Sociología del Teatro, Epistemología de las Ciencias del Teatro, Metodología, Análisis

2 Usamos mayúsculas para nombrar las ciencias como campos disciplinarios/institucionales o disciplinas individuales.

ESCENA. Revista de las artes, 2020, Vol. 80, Núm. 1 (julio-diciembre), pp.8-31 
y Crítica Teatral, Archivística y Museística Teatral, Ecdótica, Estética Teatral, Pedagogía Teatral, entre otras. También incluye la disciplina desde la que hablamos: Filosofía del Teatro³.

Hay problemas del arte que solo se los plantean las Ciencias del Arte: el análisis de las estructuras inmanentes de las obras y acontecimientos; los caminos de la creatividad artística y sus procesos; el régimen del acontecimiento artístico y la singularidad de la poiesis; la elaboración de las técnicas; la historia interna del arte y su compleja relación con la serie social (articulación entre la microhistoria del arte y las microhistorias sociales, políticas, culturales, entre otras); el ejercicio de una razón de la praxis artística (en oposición a una razón lógica y una razón bibliográfica) ${ }^{4}$; el diseño de mapas específicos de producción, distribución, circulación, flujos y otros, más allá de los mapas geopolíticos nacionales; la pedagogía artística y los secretos de la formación, ¿se puede enseñar a ser artista? La experiencia ha demostrado que las prácticas artísticas (hacer teatro, música, plástica..., gestionar las artes, enseñarlas, difundirlas, entre otras) y las Ciencias del Arte se alimentan entre sí provechosamente.

El arte reconoce su singularidad tanto en el hacer como en la producción de saberes y teorías. El teatro y su reflexión no quedan al margen de estos planteos. La investigación artística se articula, además, con la docencia y la capacitación en el arte: es sabido que nadie puede enseñar a otro a ser artista, pero es real que en el plano de la formación se transmiten técnicas, procedimientos, saberes e historia, que pueden ser aprovechados de diversas formas por un artista. En la última década hemos asistido a un verdadero cambio epistemológico respecto a la articulación entre el campo de las artes y la Universidad y esta ha ganado un nuevo protagonismo no solo en la producción de conocimiento, sino también en la praxis artística. Se ha producido una multiplicación de espacios universitarios dedicados al arte, se ha creado RAUdA (Red Argentina Universitaria de Arte) en 2011, se han afianzado institucionalmente las Ciencias del Arte $^{5}$ y se ha multiplicado el vínculo entre la reflexión científica y la

${ }^{3}$ Para ampliar las coordenadas de esta disciplina científica innovadora en breve síntesis, véase Dubatti, 2019.

${ }^{4}$ Hay una zona de la experiencia empírica que instala, a partir de la observación y la comprobación, una razón de la praxis. No una razón lógica (matemática, racional, geométrica), ni una razón bibliográfica (de autoridad libresca), sino una razón de acontecimiento, de lo que pasa. Si el teatro y el arte, desde un punto de vista filosófico, son acontecimientos singulares, su comprensión exige una razón de la praxis.

${ }^{5}$ Baste mencionar, en la Argentina, la creación de nuevas universidades, facultades, carreras, especializaciones y posgrados vinculados al arte en diversas instituciones, entre ellas, en la Universidad Nacional de Río Negro, la Universidad Nacional del Nordeste, la Universidad Nacional del Centro de la Provincia de Buenos Aires y la Universidad Nacional de las Artes. En el Instituto de Artes del 
creación teatral6. Los desafíos de la nueva investigación artística se encuadran en la "función social de la Universidad Latinoamericana" que exaltó José Luis Romero en 1959:

Unas veces la Universidad ha sido solamente un instrumento de conservación y transmisión del saber tradicional ... Pero otras veces la Universidad ha percibido y aceptado las situaciones de cambio, tanto espiritual como social. En ese caso ha renunciado a limitar sus funciones a la simple conservación y transmisión del saber tradicional, encaminando sus esfuerzos, en cambio, a la tarea de renovarlo. Por esa vía la Universidad ha mantenido o recobrado su condición de centro cultural eminente. (2004, p. 395)

La Filosofía del Teatro apunta a promover esa renovación de la Teatrología y las Ciencias del Arte. Desde su origen, la Filosofía del Teatro ha puesto el acento en el rol del artista como productor de saberes, como pensador e intelectual específico (Dubatti, 2007, párr. 70) e insustituible en la generación de un pensamiento singular, único, impar. Sucede que el artista, desde la praxis, para la praxis y sobre la praxis, produce pensamiento permanentemente, de diversas maneras, según las poéticas; es decir, según la forma de trabajo, los procedimientos estructurales y la concepción de teatro, y muchas veces es quien más sabe (o uno de los que más sabe) de teatro.

Llamamos pensamiento teatral a la producción de conocimiento que el artista, el técnico artista $^{7}$ y otros agentes de la producción teatral generan desde la praxis, para la praxis y sobre la praxis teatral. (Recordemos, en breve paréntesis, que el primer texto teórico-técnico sobre teatro del que tenemos noticia -aunque permanece perdido- es de un artista: Sobre el coro, de Sófocles, siglo V a.C., es decir, muchos años anterior a la Poética de Aristóteles, del siglo IV a.C.). Podemos distinguir un pensamiento teatral implícito en la obra, por ejemplo, en tanto metáfora epistemológica, según Umberto Eco: "el modo de estructurar las formas del arte refleja -a guisa de semejanza, de metaforización, de apunte

Espectáculo "Dr. Raúl H. Castagnino" de la UBA trabajamos prioritariamente la problemática del artista-investigador. Sigue habiendo grandes deudas en este campo: el CONICET, por ejemplo, no reconoce aún un Área de Ciencias del Arte. Véanse al respecto nuestras reflexiones en Fuentes y Silva, 2013, pp. 161-169. Hay mucho por lo que pelear todavía.

6 Un buen ejemplo son los trabajos reunidos en Mármol, M., Magri, M., Mora, A., Provenzano, M., Sáez, M.L. \& Verdenelli, J. (copiladoras). (2013). Ni adentro ni afuera. Articulaciones entre teoría y práctica en la escena del arte. La Plata, Argentina: Club Hem Editores.

7 Como hemos señalado en diversas oportunidades, la labor de los técnicos y su producción de pensamiento son fundamentales en la producción de acontecimiento teatral, por eso preferimos hablar no de técnico a secas, sino de técnico artista.

ESCENA. Revista de las artes, 2020, Vol. 80, Núm. 1 (julio-diciembre), pp.8-31 
de resolución del concepto en figura- el modo como la ciencia o, sin más, la cultura de la época ven la realidad" (1984, pp. 88-89), en el trabajo de hacerla y en la concepción de su poética, y un pensamiento teatral explícito cuando es expuesto meta-artísticamente.

Sin embargo, ese pensamiento no está solo y exclusivamente circunscrito al teatro: involucra una visión general del mundo, pero desde otro ángulo, desde la experiencia teatral. Basta con charlar unos minutos con Ricardo Bartís, Mauricio Kartun, Vivi Tellas o Rafael Spregelburd -por dar algunos nombres fundamentales- para advertir enseguida que miran y piensan el mundo desde un punto de vista inseparable de su existencia como teatristas. Importante destacarlo: el pensamiento teatral compromete tanto el pensamiento sobre lo específico del trabajo y la poética teatral, como el pensamiento sobre el mundo. Se genera una mirada comprensiva afectada por la existencia en el teatro. Hacer teatro en la Argentina no es meramente elaborar obras, sino también una forma de vivir. El teatro es en la Argentina una biopolítica, el arte como morada de habitabilidad8.

En complementariedad con lo que señala Eliot en el epígrafe que abre este artículo, ese pensamiento teatral se encarna, implícitamente, en la que denominamos "poética implícita" (Dubatti, 2014, párr. 1, 8 y 10), en su estructura, su trabajo y su concepción. También se encuentra explícitamente en el metateatro y el metadrama dentro de la obra ${ }^{9}$ y en metatextos y paratextos de los creadores: programas de mano, diarios de trabajo o bitácoras, prólogos, artículos, ensayos, declaraciones en entrevistas, cartas y correos electrónicos, entre otros, o la labor reveladora del investigador asociado a través de la elaboración de poéticas explícitas.

Creemos que el artista, muchas veces, es quien sabe más sobre su obra, tanto en lo micropoético como en lo macropoético; también, frecuentemente sobre la dimensión de la poética abstracta (Dubatti, 2010, párr. 14-33) y, en particular, sobre su propia modalidad de trabajo y su concepción. El artista es un trabajador específico (retomando la idea de Marx ${ }^{10}$ del arte como trabajo humano) y posee múltiples saberes sobre ese trabajo: saber-hacer, saber-ser y saber abstracto. Pero, los saberes de un artista van más allá de la esfera del trabajo. De allí la importancia de valorizar ese pensamiento, de estimularlo y de registrarlo

8 Un ejemplo claro de esta extensión, que involucra los más diversos aspectos de la vida y el mundo, son los artículos de Eduardo Pavlovsky en Página /12 (reunidos en sus libros Micropolítica de la resistencia, La voz del cuerpo y Resistir Cholo), o los de Rafael Spregelburd en Perfil (compilados como Apéndice a la edición de sus obras en Atuel).

9 Para la distinción entre metateatro y metadrama, véase García Barrientos, 2007, pp. 30-31.

${ }^{10}$ Para ampliar esta idea, se pueden consultar las siguientes obras de Karl Marx: Manuscritos: economía y filosofía, Escritos sobre arte, Escritos sobre literatura. 
a través de diversos recursos (volveremos sobre este tema). Esos saberes constituyen una cosmovisión a la que definimos como "concepción", la cual implica tanto la idea de teatro como la de mundo y la de las relaciones entre ambos.

Sostenemos que el pensamiento artístico/teatral implica un aporte fundamental para las Ciencias del Arte/del Teatro, que se enriquecen con este, al tiempo que multiplican sus saberes; teatro, pensamiento teatral y Ciencias del Teatro se alimentan entre sí multiplicándose. Conviven y se interrelacionan en los programas universitarios dedicados al arte. Los tres campos confluyen, de manera diversa, en una Filosofía de la Praxis Artística. Por esta razón, la disciplina científica Filosofía del Teatro impulsa el reconocimiento de cuatro figuras fundamentales en la producción de conocimiento desde/para/sobre la praxis artística. Se trata de: el artista-investigador, el investigador-artista, el artista asociado a un investigador no-artista especializado en arte y el investigador que sin ser artista produce conocimiento participando en el acontecimiento artístico, ya sea por su estrecha relación y familiaridad con el campo artístico o por su trabajo en el convivio como espectador; es el investigador que ubica su laboratorio en el acontecimiento teatral, no solo en el gabinete científico.

Ampliemos brevemente las características de estas cuatro figuras. Llamamos artista-investigador al artista (incluido el técnico artista) que produce pensamiento a partir de su praxis creadora, de su reflexión sobre los fenómenos artísticos en general, de la docencia. En el teatro argentino abundan ejemplos notables: mencionemos a Juan Carlos Gené, Eduardo Pavlovsky, Griselda Gambaro, Raúl Serrano, Alberto Ure, Mauricio Kartun, Ricardo Bartís, Rafael Spregelburd, Norberto Laino, Federico León, Eli Sirlin.

Llamamos investigador-artista al teórico con importante producción ensayística y/o científica que, además de su carrera académica, es un artista de primer nivel. Un ejemplo fundamental de la Argentina es Gastón Breyer: arquitecto, docente e investigador universitario, Doctor Honoris Causa de la Universidad de Buenos Aires y uno de los escenógrafos más relevantes y fecundos en la historia de la escena nacional. Otros casos destacables son los de Alejandro Finzi, Doctor por la Université Laval de Québec (Canadá), profesor titular de la Universidad Nacional del Comahue (Neuquén) y excelente dramaturgo con rica bibliografía teórica sobre teatro y literatura (Dubatti, 2009a, pp. 201-205); José Luis Valenzuela, director y profesor universitario radicado en Resistencia, Chaco; Cipriano Argüello Pitt, director y profesor de la Universidad Nacional de Córdoba, al frente de la sala Documenta/Escénica; Julia Lavatelli, profesora e investigadora en la Universidad Nacional del Centro, doctorada en Université Sorbonne Nouvelle y teatrista. En los últimos años, la figura del investigador-artista está proliferando gracias a un desarrollo mayor de los espacios institucionales que fomentan la investigación (por ejemplo, muchos becarios e investigadores formados del CONICET tienen, además de su trabajo como investigadores profesionales, producción artística). 
Llamamos investigador participativo - de acuerdo con el término utilizado por María Teresa Sirvent (2006) - a aquel investigador (científico, académico, ensayista, teórico o pensador en un sentido general) que sale de su escritorio, de su cubículo universitario o del aula y trabaja adentro mismo del campo teatral, como espectador, periodista, investigador de campo, gestor o político cultural. Es decir, que participa estrechamente en el hacer del campo teatral y que en muchos casos produce, más allá de su investigación específica (que se verá concretada en informes, artículos, libros, comunicaciones), contribuciones en el plano de la investigación "aplicada" a lo social, a lo político, a lo institucional, a lo legislativo, a la docencia y, muy particularmente, a la formación de público, entre otros aspectos. Creemos que cada vez más, en relación directa con la redefinición del rol universitario en el plano del arte y de las Ciencias del Arte, esta dimensión participativa de la investigación artística está creciendo.

Pero, además, el perfil participativo de un investigador puede estar dado por la asociación colaboradora con los artistas. Llamamos artista e investigador asociados a la pareja de colaboración entre un creador y un investigador (científico, académico o ensayista...) con un objetivo común relacionado a la producción de conocimiento sobre el arte. La colaboración del investigador puede exceder la producción de conocimiento y estar ligada a la creación misma (por ejemplo, cuando el investigador es convocado como dramaturgista o para trabajar integrado al equipo creativo bajo diferentes figuras, por ejemplo, la de asesor de contenidos o lecturas). En nuestro caso, venimos trabajando en asociación con diversos artistas para la generación de estudios, testimonios o ediciones sobre su obra, entre ellos Eduardo Pavlovsky (La ética del cuerpo, 2001), Ana María Bovo (Narrar, oficio trémulo, 2002), Ricardo Bartís (Cancha con niebla, 2003), entre otros. También desarrollamos esa tarea de colaboración a través de las entrevistas con los artistas y el análisis de sus espectáculos en las reuniones de la Escuela de Espectadores de Buenos Aires, todos los lunes de marzo a noviembre desde 2001, en las que intervienen desde hace varios años 340 alumnos. El artista puede sentir incluso al crítico como un asociado (tácito o declarado) en estos términos; así lo expresa Juan Mayorga en su pieza El crítico, por vía negativa y positiva, y en el metatexto incluido en el programa de mano del estreno en Buenos Aires:

Cuando empecé, leía las críticas a mis obras buscando el elogio o la absolución. Hoy espero que me enseñen algo. Acerca de la obra, de sus vínculos con otras obras -mías o ajenas-, de su relación con la época... También espero que las críticas me ayuden a corregir la obra, a rehacerla. (Mayorga, 2013)

Cinco aclaraciones. Primera: por supuesto, la tarea creadora en teatro es eminentemente grupal, por lo que se da por sentada la figura de asociación entre dos o más artistas-investigadores e investigadores-artistas. En el teatro es muy productivo e imposible de eludir o evitar, el pensar en grupo, por la naturaleza misma del trabajo teatral. Suelen darse 
casos en los que dos artistas que han trabajado juntos producen un pensamiento muy semejante o con importantes coincidencias.

Segunda: el mismo artista-investigador o investigador-artista puede producir pensamiento de manera individual, colectiva y asociarse a un especialista en arte, un ensayista o un científico para producir pensamiento. Está de más decir que una figura se cruza, superpone y convive con la otra, y que todas las prácticas del pensamiento se multiplican fecundamente.

Tercera: el asociado al artista puede ser una figura externa a la actividad artística y a las Ciencias del Arte, un artista de otra rama, o un filósofo, un sociólogo, un político, un científico de otra especialización, entre otras variables. Un ejemplo muy valioso es el del libro de diálogos del actor y director boliviano Marcos Malavia con el científico Jean-Pierre Assal (medicina): De la puesta en escena a la puesta en esencia (2009), o la rica colaboración sostenida entre Eduardo Pavlovsky y Hernán Kesselman.

Cuarta: la identificación de figuras, útil para la clasificación de tipos, no implica que no existan formas híbridas o difíciles de encasillar en el espectro de estas figuras. La idea no es "encasillar", sino tener herramientas teóricas para pensar la complejidad de lo que acontece en los campos teatrales. Un magnífico ejemplo es Eduardo Pavlovsky, sin duda, uno de los artistas más grandes de la Argentina por su dramaturgia, su actuación y su trabajo grupal. Pero, también médico (egresado de la Universidad de Buenos Aires), titulado en la APA y psicodramatista, con una vasta tarea "paralela" en terapia de grupos, autor de más de veinte libros sobre psicodrama, política, boxeo, cultura, entre otros temas. ¿Artista-investigador o investigador-artista?

Quinta: la categoría artista-investigador es extensible a todos los agentes productores dentro del campo teatral. El técnico-artista-investigador, el gestor artístico-investigador, el docente de arte-investigador, el productor artístico-investigador, el empresario-investigador, el espectador-investigador, el crítico teatral-investigador, entre otros. Por ejemplo, el productor Gustavo Schraier y su texto Laboratorio de producción teatral (2006).

Más allá de la necesaria y productiva infrasciencia (una zona del arte se habilita en un saber no concientizado), todo artista está investigando todo el tiempo, ya sea en el hacer, en la reflexión sobre el hacer o en el registro de la experiencia. Todo artista es un artista-investigador, aunque los hay de diferentes tipos según su forma de relacionarse con la explicitación del pensamiento. Destaquemos tres esenciales, a continuación.

Está el artista-investigador más silencioso, balbuceante, incluso hermético que, aunque piense su producción no tiene voluntad de verbalizar ese pensamiento o no cree en la necesidad de hacerlo. Aunque produce pensamiento, no reconoce esa función y no 
se identifica con ella, hasta se opone a desarrollarla porque cree que ese pensar lo debilita, le quita espontaneidad, "inspiración" o novedad y descubrimiento a su hacer. Muchos artistas sostienen que el arte se hace y se vive, pero no se piensa ${ }^{11}$. Es importante señalar que, a pesar de esta actitud negadora, este tipo de artista-investigador igualmente produce pensamiento en el hacer y reflexiona sobre ese hacer. Hay otro artista-investigador que, ya en forma individual, grupal o asociada, cree en la producción de pensamiento, colabora y se esfuerza por la transmisión y el registro de ese pensamiento.

Finalmente, hay un artista plenamente intelectual, que produce una literatura ensayística excepcional, reveladora, abundante y sostenida a través de los años, muchas veces muy superior en su originalidad a la producida por académicos y científicos. Proliferan los ejemplos en el teatro argentino y, por supuesto, en el internacional: lo demuestran los libros de Constantin Stanislavki, Vsevolod Meyerhold, Luigi Pirandello, Antonin Artaud, Peter Brook, Jerzy Grotowski, Eugenio Barba, entre muchísimos otros.

Preocupa, sí, el artista inhibido quien, aunque produce pensamiento considera que la tarea del pensar corresponde a otros, más formados y reconocidos como tales. Recuérdese las observaciones de Ricardo Bartís al respecto en su Cancha con niebla especialmente en "El malentendido" (2003, pp.11-12). No se trata de competir con otros intelectuales en "quién es más intelectual" o "a quién le corresponde" asumirse como tal, sino de reconocer que el pensar teatral es una tarea intelectual específica. Ojalá estas páginas contribuyan a la desinhibición de muchos artistas que pueden depararnos un pensamiento fascinante aún no explicitado; a un nuevo rol de su trabajo en la universidad. La Universidad de Buenos Aires lo está haciendo en los últimos tiempos: así lo ha demostrado otorgándoles el título Honoris Causa al cineasta y cantante Leonardo Favio, al dramaturgo y director Mauricio Kartun y al grupo de músicos-humoristas Les Luthiers. Cuando recibió su Honoris Causa, Kartun dijo en la ceremonia organizada por el Rectorado de la UBA: "Me alegra que la Universidad empieza a mirar hacia afuera". La Universidad está reconociendo el arte de otra manera y adquiriendo una nueva función en relación a las prácticas artísticas.

\footnotetext{
${ }^{11}$ Lamentablemente muchos docentes de materias prácticas y entrenamiento alimentan esta concepción negadora en sus alumnos al despreciar las materias teóricas e históricas u otorgarles un estatus menor. Esto se hace explícito en las escuelas cuando los docentes de prácticas no ceden sus horas para que los alumnos puedan aprovechar una conferencia o las actividades de un congreso de historia. Hemos comprobado esta actitud de muchos colegas en carne propia.
} 


\section{Pensamiento teatral sustentado y no sustentado por las prácticas artísticas}

Ya hemos señalado, en el estudio de los casos particulares de Maurice Maeterlinck, Ricardo Rojas, Eduardo Pavlovsky, Eduardo Rovner y Javier Daulte, lo reveladora que resulta la confrontación entre práctica y teoría teatral en diferentes niveles de análisis ${ }^{12}$. El diálogo con Eduardo Pavlovsky cambió el rumbo de nuestra tesis doctoral y modificó su escritura, así como significó el origen de nuestra reflexión sobre la Filosofía del Teatro. Me tomo el permiso de usar, para esta historia en excursus, pero ilustrativa, la primera persona. A fines de 1993 me puse en contacto con el gran actor y dramaturgo de El señor Galíndez. No imaginaba entonces que, en adelante, trabajaríamos juntos, artista e investigador, hasta su muerte, en 2015. Por teléfono, temblando, en verdad, por mi absoluta admiración, y porque era la primera vez que hablaba con él personalmente, le expliqué a Pavlovsky que iba a presentar los papeles para aspirar al doctorado en la Universidad de Buenos Aires y que había elegido como tema su teatro. Le pedí si podía darme una reunión para contarle más detalles, consultarle dudas y solicitar su colaboración. Yo quería -le adelanté- hacerle una larga entrevista sobre su historia, hablar con él de poética, política, psicodrama, dictadura, exilio español, desexilio (entrevista que terminó siendo uno de nuestros primeros libros: La ética del cuerpo, 1994). Pavlovsky accedió generosamente.

Llegué a la casa donde vivía y donde funcionaba, además, en un salón lateral con acceso autónomo, su consultorio psicodramático, muy cerca de los Lagos de Palermo. Pavlovsky me hizo pasar al living. Desde el sillón donde me senté veía a través de una gran ventana, al fondo de la amplia casa, un jardín y una pileta de natación. Emocionado, agradecido por el encuentro, le comenté que venía desde los años ochenta siguiendo sus espectáculos y sus libros, que había visto varias veces sus obras Potestad, Pablo, Paso de dos... (actuadas por él mismo), que además había acopiado las ediciones de sus textos dramáticos y ensayísticos (muchos de ellos comprados en los mismos teatros donde se presentaban los espectáculos, a la salida de las funciones), así como toda la bibliografía internacional sobre su obra que había caído en mis manos. Le expliqué que, como espectador, el interés que sentía por su teatro me había llevado a elegirlo como tema de doctorado.

“¿Y qué vas a estudiar?”, me preguntó. Como yo venía de una formación semiótica (en ese entonces, la Semiótica era la línea hegemónica en la Teatrología argentina), le contesté, sin tenerlo muy claro, y sin tutearlo todavía: "Quiero analizar su teatro, Pavlovsky, desde la perspectiva de la comunicación".

${ }^{12}$ Dubatti, 1990, 2003, 2004, 2009b y 2017, respectivamente. 
Universidad y Filosofía de la Praxis Artística: Teatro, pensamiento teatral,

Artículo Ciencias del Teatro

"Está bueno -me dijo-, pero, en verdad, a mí la comunicación no es lo que más me interesa".

"¿Cómo? -pregunté yo, que no esperaba ese revés-, ¿su teatro no comunica?"

"Sí, comunica, pero no es lo más importante de mi teatro. Yo hago teatro porque, si no, me muero. Para mí el teatro es la vida. El teatro, más que comunicación, es un acontecimiento existencial. Lo peor que me podría pasar es levantarme un día sin deseo de hacer teatro. La mayor intensidad de mi vida la encuentro en hacer teatro en grupo. Es mi micropolítica. Cuando actúo es cuando me siento más vivo y conectado pluridimensionalmente con el mundo. Pura multiplicidad existencial. Para mí el teatro es mi existencia".

Recuerdo cómo salí perturbado, en muchos aspectos, de aquella primera entrevista. Feliz, porque durante la reunión Pavlovsky había aceptado grabar las conversaciones de La ética del cuerpo, ya habíamos fijado fecha para la primera charla, me había mostrado su biblioteca y puesto su archivo a mi disposición, y iregalo inconmensurable!: me había invitado a asistir a los ensayos de Rojos globos rojos, la nueva obra que estrenaría en el Teatro Babilonia, en 1994, con dirección de Rubens Correa y Javier Margulis, sobre la que estaban trabajando. Nuestro primer libro fue, justamente, la publicación de Rojos globos rojos, bajo el flamante sello de Ediciones Babilonia.

Pero, también me sentía preocupado, desconcertado. Resonaban en mí las palabras de su planteo inicial. En lugar de comunicación, lenguaje y signos, Pavlovsky había puesto el acento en otros conceptos: vida, acontecimiento, existencia, deseo, intensidad, grupo, micropolítica, multiplicidad. Era la primera vez que escuchaba hablar del teatro no como lenguaje, sino como acontecimiento. También había hablado de cuerpo, reunión, afectación, experiencia, ética del cuerpo, tiempo, pérdida, muerte. Mientras caminaba por la calle Sucre hacia Barrancas de Belgrano para tomar el colectivo hacia mi casa, ya sabía que necesitaba replantear la base epistemológica desde la que estudiar a Pavlovsky, pero no cómo lo iba a hacer. Sus palabras me habían abierto la mirada hacia otra concepción, otra forma de entender el teatro como espacio de existencia, experiencia y subjetivación. En 1993 ningún teatrólogo europeo de los que entonces leía hablaba en estos términos. Lo hacía un artista, un artista excepcional y con una solidez teórica incontrarrestable.

Ya en casa, busqué en el "estante Pavlovsky" de mi biblioteca su ensayo Reflexiones sobre el proceso creador (1976) y lo releí. Encontré allí observaciones que antes había pasado por alto sobre el teatro como acontecimiento y experiencia, en la misma línea teórica de la que acabábamos de hablar. Por ejemplo, cuando Pavlovsky se refiere a su actuación en El señor Galíndez.

No somos [en la actuación] un "como si" de la vida, sino que somos "nosotros mismos", en nuestros sueños, en nuestras desesperanzas, en nuestras alegrías, en

ESCENA. Revista de las artes, 2020, Vol. 80, Núm. 1 (julio-diciembre), pp. 8-31 
nuestras angustias; personaje y persona se confunden en un movimiento dialéctico que intenta transmitir lo más profundo e íntimo del actor. (Pavlovsky, 1976, pp. 41-42)

En esas páginas fundamentales para su trayectoria, Pavlovsky se auto-observa y analiza que, cuando llega a hacer la función, luego de un largo día de trabajo como psiquiatra y psicodramatista,

mi fatiga física y mental es enorme ... Me toca el turno, camino unos metros y entro en el escenario. Una nueva energía parece apoderarse de todo mi ser; desaparece mi cansancio, mi fatiga ya no me pertenece, "no está en mi cuerpo" ... La sensación es de transformación mágica. ¿Qué pasó en mi cuerpo? ¿De dónde surge esa vitalidad tan instantánea? ¿Qué línea divisoria entre la realidad y lo imaginario permite esa mutación? ... Mutación fantástica, donde el teatro se me aparece como un gran receptor de otros mundos, personajes imaginarios, retazos oníricos, que me permiten explorar otros contextos, otros momentos, otras dimensiones... Por eso el teatro seguirá representándose siempre, porque en el espacio escénico nada es tan absolutamente ficción y nada es tan absolutamente real. (Pavlovsky, 1976, pp. 43-44)

Ya está inscripta, implícitamente, en este ensayo de 1976, su teoría posterior del teatro de estados. Por lo que Pavlovsky indicaba, tanto en su ensayo como en la entrevista, que la Semiótica no era exactamente el camino para comprender lo que él llamaba acontecimiento teatral; tampoco el psicoanálisis. Había que encontrar otra senda... Era la Filosofía, en cuyo sistema los términos existencia y acontecimiento eran claves. Inicié entonces una búsqueda en la que Pavlovsky fue un gran aliado, tanto para la tesis como más allá de la tesis.

Volvamos al curso central de estas reflexiones. También señalamos cómo la producción de pensamiento teatral/artístico y las prácticas tienen mutua productividad: pensamiento y creación se multiplican entre sí, uno engendra al otro, o son recursivos hasta tal punto que ya no podemos saber cuál fue primero o qué determina a qué. Pero, la relación entre el pensamiento y la práctica puede ser más compleja que la simple complementariedad iluminadora. Puede existir un desfasaje o incluso una oposición entre práctica y pensamiento. Por ello el estudioso tiene que estar alerta y no dar por sentada esa supuesta complementariedad o correlación "natural" entre el pensar y el hacer, entre lo que el artista dice que hace y lo que hace realmente. Veamos cuatro casos muy frecuentes:

1. El artista-investigador que produce excelentes ensayos teóricos, pero su praxis no es tan relevante. Su pensamiento teórico es más valioso que su creación y el valor de su teoría no es trasladable a su obra práctica. El pensamiento no se sostiene en la producción artística. Caso: suele darse con frecuencia en la docencia un excelente docente de dirección que no sobresale como director. 
2. El artista-investigador que sostiene dentro de su pensamiento que hace en la práctica algo que en realidad no hace. Auto-atribuye a su obra determinadas observaciones, contenidos o rasgos (incluso valores) que no se verifican en la obra misma. Caso: un director que dice hacer "teatro posdramático" y en realidad no lo hace. Decimos vulgarmente que en estos casos el artista evidencia moverse en un mundo propio, no compartido, en una suerte de "artistalandia".

3. El artista-investigador que elabora, a partir del ejercicio de la memoria, un relato sobre la propia historia y sobre la historia del teatro que, luego, la investigación científica desmiente o rectifica. Como señala Beatriz Sarlo en Tiempo pasado, la historia compite con la memoria:

El pasado es siempre conflictivo. A él se refieren, en competencia, la memoria y la historia, porque la historia no siempre puede creerle a la memoria, y la memoria desconfía de una reconstrucción que no ponga en su centro los derechos del recuerdo (derechos de vida, de justicia, de subjetividad). (2005, p. 9)

Caso: los artistas que afirman que en la década de los años noventa el teatro "político" desapareció en la Argentina y que ellos eran los únicos que hacían teatro político o que gracias a ellos el teatro político "regresó".

4. El artista-investigador que realiza observaciones sobre otros artistas, observaciones que, más que valer para la comprensión de esos otros artistas, valen para entender al mismo artista-investigador, porque en realidad está formulando, indirectamente, claves sobre sí mismo; una suerte de auto-referencia en clave, por vía positiva o negativa. Caso: los artistas del teatro independiente que niegan la posibilidad de un "teatro comercial de arte"; su negación no quiere decir que ese "teatro comercial de arte" sea imposible, solo ilumina su propia concepción radicalizada del valor del teatro independiente.

Un ejemplo notable de desfasaje puede hallarse entre teoría y práctica de Bertolt Brecht respecto del Verfremdungseffeket o "efecto de distanciamiento" (Dubatti, 2013). Se trata entonces de comprobar si el pensamiento teatral de un artista es sustentado o no sustentado por sus prácticas artísticas, por la realidad histórica o por las dinámicas de la diversidad en el campo teatral. El investigador no-artista debe asumir una posición crítica, no una adhesión acrítica y mecánica, frente al pensamiento teatral enunciado por los artistas. Esa posición crítica implica una ética diferente para el artista-investigador y para el investigador no-artista (científico, académico, ensayístico) (Dubatti, 2017, párr. 28 y 29).

Pero, es importante dejar claro que, más allá de cualquier objeción analítica de no sustentación, si al artista le sirve generar ese pensamiento para producir su propia obra, 
el pensamiento es válido en esa dimensión interna: para pensar las coordenadas de la producción de ese mismo artista ${ }^{13}$. Un ejemplo claro surge cuando un artista cuestiona arbitrariamente la obra de otro artista: más allá de que los parámetros con que evalúa y analiza puedan no ser los adecuados, ni sus observaciones pertinentes o ajustadas al objeto referido, si a él le sirve para afianzar su cosmovisión o su poética, bienvenidas sean sus observaciones.

Sin duda, de estas afirmaciones volvemos a concluir: en la investigación es relevante pensar las prácticas, pensar el pensamiento teatral y pensar las relaciones entre prácticas y pensamiento teatral. Pero, el investigador no-artista debe asumir una posición crítica, verificadora, analítica y no meramente complaciente o reproductora de los dichos del artista.

\section{El artista como intelectual específico y su relación complementaria con la crisis del artista "ilustrado"}

El hecho de que el artista se reconozca como productor de pensamiento teatral e intelectual específico (Dubatti, 2007, párr. 70) no quiere decir que se reconozca como "ilustrado". Justamente el ascenso del (auto)reconocimiento intelectual está vinculado a la crisis de la identificación con el "teatrista ilustrado".

En el teatro argentino se afianzaron durante décadas los discursos que validan al artista como un guía político, moral y humano de la sociedad argentina. Llamamos "teatrista ilustrado" o "teatrista-autoridad" a esa función de referencia que, más allá de los saberes específicamente teatrales, es asumida por numerosos creadores del teatro argentino, directa o indirectamente, con mayor énfasis desde 1930 y en especial en el teatro independiente (Dubatti, 2012, pp. 83 y 100). Dicha función manifiesta una marcada crisis en el teatro de la Posdictadura (desde 1983 hasta hoy) y muy especialmente en el teatro actual.

La función del "teatrista ilustrado" o "teatrista-autoridad" es encarnada por los artistas, atribuida o reclamada a ellos por cualquiera de los agentes del campo teatral. Se trata de una función que los artistas se otorgan entre sí: a veces se la autoatribuyen (por ejemplo, "mi teatro cumple esta función"), o por humildad se la delegan a otros creadores ("el teatro de mis colegas cumple esta función"), o la generalizan ("el teatro cumple o debe cumplir

\footnotetext{
${ }^{13}$ Por supuesto, consideramos inaceptable desde todo punto de vista y repudiable en todo sentido el pensamiento teatral antidemocrático, racista, antisemita, xenófobo o que vaya en contra de los Derechos Humanos, como el del justamente objetado cómico francés Dieudonné. Recuérdese que entre los criterios de valoración destacamos el ideológico (Dubatti, 2010, p. 40) y, especialmente, (p. 182).
} 
esta función"), o en actitud crítica confrontativa la demandan ("el teatro debería cumplir esta función"). Por otra parte, les es atribuida a los artistas por los otros agentes del campo: los técnicos, los productores, los espectadores, los críticos, los gestores, los funcionarios institucionales, entre otros. La función del teatrista ilustrado o autoridad otorga a quienes hacen teatro (especialmente a los dramaturgos, a los directores y a los actores) saberes sociales, políticos y humanos jerarquizados, así como una eficaz capacidad educativa para transmitirlos, tanto en aspectos temáticos particulares, como en la formación general -política, cívica y moral- de la sociedad.

Según esta función, al constituirse en autoridad, el teatrista cumple una misión que lo equipara a un maestro y por extensión a un guía de la sociedad. La función del teatrista ilustrado se fundamenta en algunos supuestos: en tanto guía y maestro. El hacedor de teatro tiene aquellos saberes que se consideran pertinentes para orientarse y desempeñarse en el campo social, moral y político, y asume por vocación y misión la función de transmitirlos. El artista-maestro sabe más que el espectador-alumno y eso justifica su función: conoce y reconoce qué debe hacerse y, en consecuencia, indica al espectador qué decisiones se deben tomar, qué posiciones asumir, qué situaciones cuestionar y qué desafíos encarar, dentro de qué cartografía de valores ubicarse; su teatro tiene la capacidad de encarnar esos saberes con pertinencia, de transmitirlos y comunicarlos objetivamente. El espectador-alumno asiste al teatro con la finalidad de adquirir esos saberes que no posee, de ver aquello que no puede ver de otra manera, o que no quiere ver, o también el espectador tiene la posibilidad de ratificar (si es "formado" y coincide con el maestro) lo que ya sabe a través de la confrontación de sus saberes con los de la autoridad teatral. La función del teatrista ilustrado es una variante contemporánea, compleja y facetada, de la concepción ancestral del teatro como escuela. Usamos el término "ilustrado" no en el sentido tradicional (sinónimo de erudito, académico o ligado al movimiento de la llustración), sino en su acepción más específicamente artística: sabio, informado, lúcido. Los saberes del teatrista autoridad no necesitan provenir de la formación académica o intelectual (no siempre frecuente en los artistas nacionales): su ilustración puede provenir de los saberes del autodidacta, pero está avalada por los campos de la política, del arte, del humanismo, del "pueblo," según cada caso.

Esta función se torna explícita, por ejemplo, a partir de 1930 en las declaraciones y escritos de Léonidas Barletta, el fundador del Teatro del Pueblo, quien reivindica la figura del teatrista-autoridad durante toda su actividad al frente de dicha formación, entre 1930 y1975, y quien sienta las bases del movimiento del teatro independiente, que en la Argentina sigue vivo -con sustanciales transformaciones- hasta hoy. Los independientes impusieron un concepto del arte de raíz moderna, por la que el teatro es un instrumento para transformar la sociedad y dignificarla, al servicio del progreso, la educación, la moral, la política, la 
ciencia, una concepción utópica, anticonformista y utilitaria del teatro. En 1964, en Rosario (provincia de Santa Fe), en el marco del Festival Nacional de Teatros Independientes, Barletta realiza el discurso de apertura, en el que afirma:

Debo expresar ante todo que independiente es la más alta categoría que se puede alcanzar en materia de teatro. No desconocemos la labor de los profesionales, filodramáticos, aficionados, estudiantiles y oportunistas que empollan en cuanto nido encuentran deshabitado; pero independientes son aquellos artistas que, conscientes de la importancia social del arte, costean con su sacrificio personal la posibilidad de que el teatro, la más alta escuela de la humanidad, llegue al espectador en su máxima pureza. Estos son los verdaderos profesionales, aunque carezcan de empresarios, aunque no puedan vivir dignamente de su profesión, porque el país no cotiza dignamente la actividad artística y solo paga malamente el histrionismo, el espectáculo cuya misión es distraer al público de los problemas fundamentales que lo aquejan. El teatro independiente se siente responsable dentro de la formidable transformación que se opera, en la liquidación de viejos y carcomidos conceptos y en la constante renovación de valores. Queremos llevar el arte puro al corazón del pueblo, ser rectores de su comportamiento, inspirarlo en el bien, en la justicia, en la generosidad, encendiendo en su alma un ansia de superación moral. (citado por Larra, 1978, p. 106)

La autoatribución de valores del artista ilustrado establece la idea de que el creador teatral accede por su trabajo, sus reflexiones, su militancia y sus condiciones al conocimiento de la verdad, esto lo hace "puro" en su ética y le permite saber más que el espectador, al que debe mostrarle el camino correcto. El teatro se transforma así, al decir de Barletta, en "la más alta escuela de la humanidad," y el artista en un educador, un guía, un rector, un ejemplo para la sociedad. Por eso, los independientes reivindican su autoconciencia, su teoría, su "ética" y su "principiología" que los diferencia de los filodramáticos y vocacionales (Marial, 1955, p. 18), su capacidad de organizarse, su voluntad de lucha y militancia, su agonismo a costa del sacrificio personal, su responsabilidad histórica y los valores y certezas que representan, su coherencia, incluso su dimensión "salvífica", como afirma Marial en su libro El teatro independiente, escrito en ocasión de los primeros 25 años de historia del movimiento: "Se trataba nada más -y nada menos también- que de salvar al teatro" (1955, p. 36).

Lo cierto es que, en el teatro contemporáneo, especialmente en el período de la Posdictadura, numerosos teatristas argentinos ya no reivindican para sí ni atribuyen a sus colegas un rol de autoridad ni de "conciencia", sino por el contrario se asumen infrascientes, desprovistos de certezas que transmitir a los espectadores y no se identifican con la función de indicarles a otros el camino a seguir. Uno de ellos es el director Ricardo Bartís, quien en su libro Cancha con niebla (2003) exalta el acontecimiento teatral como campo poético propositivo en sí mismo, pero no rescata su función pedagógica de transmisión de certezas 
ni de enseñanza al espectador, y menos la autocolocación del teatrista como "maestro" del público. Con diferencias, pero en una línea complementaria de divergencia con la figura del "teatrista ilustrado", Mauricio Kartun propone una poética política en El niño argentino (2006), Ala de criados (2009) y Salomé de chacra (2012), en las cuales plantea un pasaje de un teatro de la imposición de convicciones políticas a otro de la exposición de cómo funciona el mundo políticamente. Kartun lo llama "un teatro del ladrillazo a la vidriera" y lo define como un "teatro político de hoy [que] no habla como aquel [de los años setenta] de recetas que deben ser aplicadas para llegar a determinado resultado" (Kartun, 2006, pp. 168-169), que multiplica la potencia persuasiva del teatro político porque si bien expone o exhibe concepciones y actitudes de los personajes, voces y situaciones, desmonta su carácter de imposición.

Otro exponente de la expresión de la crisis del teatrista ilustrado es Javier Daulte, quien ha expuesto minuciosa y lúcidamente sus ideas al respecto en el ensayo "Juego y compromiso" (2010, pp. 119-139), cuyas tres partes ("La verdad" "La responsabilidad" y "La libertad") fueron escritas entre mediados de 2001 y finales de 2003. La poética explícita que Daulte enuncia en estos textos se ve ratificada en un ensayo posterior: "Batman versus Hamlet. El argumento al servicio del procedimiento y el contenido como sorpresa" (2012, pp. 64-86). Escribe Daulte sobre la "donación de la libertad del acto creativo", fenómeno que, con su apertura y mayor indeterminación, ha desplazado a la pretérita preocupación por comunicar un mensaje determinado y preciso, y no pretende transmitir una información de manera tal que el lenguaje garantice la efectividad de esa comunicación y su impacto en el receptor:

Si queremos que nuestra obra/pensamiento trascienda, ¿no deberíamos entonces atender un poco al deseo del otro? ... La respuesta es no. Porque ese elemento vinculante no puede ser a priori, ya que se trata justamente de un elemento a ser creado. Y ese acto de creación es donación para quien quiera tomarla. ¿Pero donación de qué? No es donación de contenido alguno, sino de un gesto, el gesto de la libertad del acto creativo. Lo voy a decir de manera tajante: la única verdadera donación es donación del ejercicio de la libertad de hacer lo que al artista se le antoja; donación que no es para algunos, tampoco para todos, sino para cualquiera... El cualquiera es bastante más concreto y tiene menos tufillo fascista que el algunos y es claramente menos voluntarista que el todos... Ese acto de donación es una obligación ante todo ética y militante... Lo que al artista se le antoja es producto de una conquista desplegada a lo largo de toda una obra/pensamiento y no el capricho de una tarde. (2010, p.138) (Ios subrayados son de Daulte) 
Finalmente destaquemos la posición de Rafael Spregelburd frente al tema. Reflexionando sobre Acassuso, dice Spregelburd:

[En mi teatro] no se trata de [crear] máquinas sígnicas, semióticas, que transmitan mensaje alguno (soy incapaz de tener ese mensaje para dar), sino cuerpos vivos, con comportamientos impredecibles, pero orgánicos, que ayuden a agrandar la intuición de una zona borrosa en nuestras comunidades de sentido, una zona ausente (una 'fuerza' ausente), una pantalla vacía que opera como garante de nuestros cálculos racionales, que se proyecta sobre esta. (2008, p. 287)

Por extensión, también se cuestiona hoy en la Argentina la capacidad pedagógica/ pedagogizante del teatro. El dramaturgo y director Matías Feldman reflexionó sobre su obra Hacia donde caen las cosas (2011) cuando lo entrevistamos en la Escuela de Espectadores de Buenos Aires: "Hacemos un teatro de avanzada política para la clase media que lo aplaude y esa misma clase media después vota a Mauricio Macri” (comunicación personal).

Bartís, Kartun, Daulte y Spregelburd tienen en común que no asumen la transmisión teatral de una verdad a enseñar, sino la construcción poética de dispositivos de estimulación, de exposición, de "donación" a partir de los cuales el espectador produce su propia cantera de sentido. Esto no quiere decir que los teatristas no tengan su posición política, su ideología, o crean en determinada verdad. Sencillamente, por el fenómeno de la crisis del teatrista ilustrado, no se sienten habilitados para decirle al espectador cómo tiene que ver las cosas o cómo debe conectarse con la verdad. Invitan al espectador a producir su propia respuesta, su propia creación, frente al mundo poético político que se despliega ante sus ojos.

Se ha establecido, en los últimos tiempos, un movimiento complementario, y en cierto aspecto compensatorio, entre la crisis del teatrista ilustrado y la afirmación del teatrista como un intelectual específico. No hay contradicción al respecto. La declinación de la figura del teatrista ilustrado no desmiente o desestima las capacidades del artista intelectual. Por el contrario, sucede que se trata de roles en campos diferentes y si bien se abandona la antigua dimensión de teatrista-autoridad o guía, la nueva producción de pensamiento permite al artista asumir otras posiciones frente al problema de la autoridad, la guía política, moral y social, así como la pedagogía, la comunicación y la difícil transmisión de certezas. Desde el lugar que más domina: el específico, el artista piensa su tiempo, la historia, la realidad nacional e internacional, las poéticas teatrales y el espacio del teatro en este mundo, así encarna nuevas políticas y formas de pensamiento que son consecuencia, proyección y desafío en las encrucijadas de la contemporaneidad y el futuro. Incluso desde ahí puede construir otra relación con una orgánica política. Asumir complementariamente la crisis del teatrista ilustrado y la afirmación del teatrista como intelectual específico, creemos, abre al arte posibilidades de expresión política más efectivas y potentes en cuanto a aquello que puede aportar su singularidad. 
Universidad y Filosofía de la Praxis Artística: Teatro, pensamiento teatral,

Artículo

Ciencias del Teatro

\section{La articulación de una investigación artística para el artista-investigador: formas discursivas}

El profesionalismo y la irradiación a los que han llegado los fundamentos teóricos, metodológicos y epistemológicos de los investigadores-artistas o de los investigadores no-artistas especializados en arte están a la vista en la multiplicación de carreras y especializaciones de grado y posgrado, centros de investigación, congresos, publicaciones especializadas, intercambios internacionales, en todo el país. Prosperan, en cartografía multipolar, diferentes en cada polo, líneas, temas de estudio, formas de trabajo diversas. Manifestación de un pensamiento cartografiado, de una cartografía radicante.

No puede decirse lo mismo respecto de cómo se articula el trabajo del artista-investigador, que continúa siendo uno de los desafíos para el futuro. Es importante, en ese sentido, darle al artista-investigador, a la par de la conciencia sobre la relevancia de su función productora de un pensamiento específico, herramientas que le permitan explicitar ese pensamiento y articularlo de diversas maneras. Nuestra experiencia en la dirección académica de los Departamentos de Arte y en la coordinación del Área de Investigaciones en Ciencias del Arte (AICA) del Centro Cultural de la Cooperación Floreal Gorini nos permite estar en contacto permanente con los teatristas que son programados en el CCC. A todos ellos les pedimos que no se limiten a gestar y estrenar un espectáculo, que acompañen el trabajo creador con el registro de la producción de pensamiento teatral. Explícitamente se los hace conscientes de su potencial como investigadores e intelectuales específicos. Se les pide que auto-observen el universo de su trabajo, de sus procedimientos poéticos y sus concepciones, o que observen el trabajo de otro artista, de un problema del campo teatral, político, cultural, entre otros asuntos y escriban uno texto o varios sobre algunos de los aspectos que surjan de esa (auto)observación y que consideren destacables. Los trabajos de los artistas-investigadores se han desarrollado en diferentes formas discursivas:

- El diario de trabajo o cuaderno de bitácora, que pone el acento en los procesos, las técnicas y los métodos empleados para la elaboración de un espectáculo y se presenta como una acumulación más o menos fragmentaria e inconexa de observaciones.

- La recopilación de pretextos (borradores, esbozos) y paratextos (textos escritos en paralelo a la experiencia de creación, incluso de diferentes géneros discursivos: poesía, música, plástica, periodismo, cine, fotografía, televisión, entre otros) para un análisis genético de los espectáculos teatrales estrenados.

- la composición de metatextos sobre el espectáculo teatral o, en general, sobre el teatro, bajo la forma de aforismos, notas y artículos, apuntes, correos elec- 
trónicos, editorializaciones (programas de mano, folletos, orientaciones para el espectador o la prensa), manifiestos, ensayos, libros, entrevistas, videos e incluso espectáculos-conferencias (como en el caso de la coreógrafa Mariela Ruggeri).

- La escritura histórica a partir de la memoria del artista, del grupo y el testimonio sobre las experiencias en el campo artístico, acompañada por la confección de un archivo de documentación que incluye lo audiovisual.

- La investigación sobre temas históricos, técnicos o de política cultural, que incluyen trabajo de campo, archivo y gestión, entrevistas o el estudio sobre la poética de un maestro.

Muchos artistas se capacitan para adquirir saberes investigativos (científicos, académicos, ensayísticos...) "en paralelo" a su actividad artística. El CCC implementa, al respecto, seminarios; talleres de investigación, de escritura académica, ensayística, de uso de la biblioteca y de las técnicas digitales. Así, han surgido trabajos muy valiosos de pensamiento teatral, varios de ellos publicados en la Revista del CCC en Línea (en particular, en la Sección "Palos y Piedras"), a la que se accede por la página web del CCC (www.centrocultural. coop).

En conclusión, debemos rescatar el pensamiento teatral producido desde una Filosofía de la Praxis por los artistas y agentes productores del campo teatral. Debemos estimular la producción de ese pensamiento, así como su edición y conservación, y ponerlo en multiplicación con las Ciencias del Teatro. La Universidad, en su dimensión innovadora, debe producir Arte, pensamiento artístico, Filosofía de la Praxis Artística y Ciencias del Arte, o en nuestro campo específico: Teatro, pensamiento teatral, Filosofía de la Praxis Teatral y Ciencias del Teatro, no como campos separados sino fecundamente integrados.

\section{Referencias}

Bartís, R. (2003). Cancha con niebla. Teatro perdido: fragmentos. Buenos Aires: Atuel.

Daulte, J. (2010). Juego y compromiso. En O. Cosentino (ed.), La puesta en escena en el teatro argentino del Bicentenario (pp. 119-139). Buenos Aires: Fondo Nacional de las Artes

Daulte, J. (2012). Batman versus Hamlet. El argumento al servicio del procedimiento y el contenido como sorpresa. En C. Quenta y O. Rocha (eds.), Teatro contemporáneo: provocaciones y encuentros (pp. 64-86). La Paz: Fundación Simón I. Patiño / Festival Internacional de Teatro de La Paz (FITAZ) / Carrera de Literatura de la Universidad Metropolitana de San Andrés (UMSA) e Instituto de Investigaciones Literarias (IIL).

ESCENA. Revista de las artes, 2020, Vol. 80, Núm. 1 (julio-diciembre), pp.8-31 
Universidad y Filosofía de la Praxis Artística: Teatro, pensamiento teatral,

Artículo

Ciencias del Teatro

Dubatti, J. (1990). Teoría y práctica teatrales en la obra de Eduardo Rovner. En Centro Argentino de Investigaciones en Arte (comp.), Actas de las // Jornadas de Teoría e Historia de las Artes (pp. 280-289). Buenos Aires: Editorial Contrapunto.

Dubatti, J. (2003). El convivio teatral. Teoría y práctica del Teatro Comparado. Buenos Aires: Atuel.

Dubatti, J. (2004). El teatro de Eduardo Pavlovsky: poéticas y política (Tesis para optar por el grado de doctor en Historia y Teoría de las Artes). Universidad de Buenos Aires, Argentina. Recuperado de http://repositorio.filo.uba.ar/handle/filodigital/1568

Dubatti, J. (2007). Filosofía del Teatro I. Convivio, experiencia, subjetividad. Buenos Aires: Atuel.

Dubatti, J. (2009a). Alejandro Finzi, teórico del teatro: Bibliografía. En A. Finzi, Tablón de estrellas (pp. 201-205). Buenos Aires: Colihue Teatro

Dubatti, J. (2009b). Concepciones de teatro. Poéticas teatrales y bases epistemológicas. Buenos Aires: Colihue Universidad.

Dubatti, J. (2010). Filosofía del Teatro Il. Cuerpo poético y función ontológica. Buenos Aires: Atuel.

Dubatti, J. (2012). Cien años de teatro argentino. Desde 1910 a nuestros días. Buenos Aires: Biblos-Fundación OSDE.

Dubatti, J. (2013). O teatro de Bertolt Brecht na Argentina: observacoes sobre o Teatro Comparado. En J. P. Alcantara, M. Isaacsson, et al. (eds.), O Espectador Criativo: Colisao e Diálogo (pp. 104-113). Porto Alegre: AGE Editora.

Dubatti, J. (2014). Filosofía del Teatro III. Cuerpo poético y función ontológica. Buenos Aires: Atuel.

Dubatti, J. (2017). Javier Daulte, artista-investigador: una Filosofía de la Praxis Teatral. Teatro: criação e construção de conhecimento, 5(2), 107-117.

Eco, U. (1984). Obra abierta. Barcelona: Ariel.

Eliot, T. S. (1994). Los poetas metafísicos y otros ensayos sobre teatro y religión (Vol. 1). Buenos Aires: Emecé.

Fuentes, T. M. V., \& Silva, A. (2013). Jorge Dubatti: 'Lo teatral no es solamente hacer obras de teatro, sino una manera de estar en el mundo'. Aura. Revista de Historia y Teoría de las Artes, 1, 161-169.

ESCENA. Revista de las artes, 2020, Vol. 80, Núm. 1 (julio-diciembre), pp. 8-31 
García Barrientos, J. L. (2007). Análisis de la dramaturgia. Nueve obras y un método. Madrid: Fundamentos/RESA

Kartun, M. (2006). El Niño Argentino. Buenos Aires: Atuel.

Larra, R. (1978). Leónidas Barletta, el hombre de la campana. Buenos Aires: Conducta.

Marial, J. (1955). El teatro independiente. Buenos Aires: Alpe.

Mayorga, J. (2013). El espectador, el crítico, el artista. [Programa de mano]. Buenos Aires: Teatro San Martín.

Pavlovsky, E. (1976). El señor Galíndez. Buenos Aires: Editorial Proteo.

Pavlovsky, E. (1994). Rojos globos rojos. Buenos Aires: Ediciones Babilonia.

Romero, J. L. (2004). Función social de la Universidad latinoamericana. En L. A. Romero (comp.), La experiencia argentina y otros ensayos (pp- 395-400). Buenos Aires: Taurus.

Sarlo, B. (2005). Tiempo pasado. Cultura de la memoria y giro subjetivo. Una discusión. Buenos Aires: Siglo Veintiuno.

Sirvent, M.T. (2006). El proceso de investigación. Universidad de Buenos Aires: Facultad de Filosofía y Letras.

Spregelburd, R. (2008). La paranoia. Heptalogía de Hieronymus Bosch VI. Buenos Aires: Atuel. 